The Journal of Public Space

ISSN 2206-9658

2019 | Vol. 4 n. 2

https://www.journalpublicspace.org

\title{
EDITORIAL
}

\section{Public Space in the Entrepreneurial City}

\author{
Maurice Harteveld \\ Delft University of Technology, Department of Urbanism, The Netherlands \\ m.g.a.d.harteveld@tudelft.nl \\ Hendrik Tieben \\ The Chinese University of Hong Kong, School of Architecture, Hong Kong \\ hktieben@cuhk.edu.hk
}

This issue of The Journal of Public Space explores the relationship between public space and entrepreneurship. The ideas developed during the Habitat III Conference in Quito, when considering: how to implement the ambitious aims of the New Urban Agenda in context of the current socio-economic realities and to reach a fairer share of the benefits brought by urbanisation? In December 2017, the organisation of the 10th Conference of the International Forum on Urbanism (IFoU) at the Chinese University of Hong Kong offered an opportunity to discuss such questions with international scholars and professionals. The papers in this special issue originated from this conference and later submissions to The Journal of Public Space. The theme 'Public Space in the Entrepreneurial City' was chosen based on the following three observations.

\section{Entrepreneurial action of public governments}

The entrepreneurial way of governmental action had been illuminated since the 1980s, following among others John Mollenkopf's review on Modern urban history through the lens of the entrepreneurial triumph of the American city. Within this context, David Harvey brought the trend to the current and described the trend globally as "[...] local governmental powers [that] try and attract external sources of funding, new direct investments or new employment sources” (Mollenkopf, 1983: 14, 4I-46; Harvey, 1989: 7). In the following years, the 'entrepreneurial city' continued to be approached and discussed critically in the context of a clear shift of the public sector taking over characteristics once distinctive to the private sector: Cities acting as entrepreneurs - risk-taking, inventiveness, promotion and profit motivation - while shifting planning responsibilities to a small number of private actors (Hall and Hubbard, 1998: 153). This was seen as one of the reasons for the increasing inequality in cities, questioning the right to the city. The 'entrepreneurial city' as such led particularly to new spatial conditions and typologies as governments delegated the responsibilities for the production and management of public space to private actors. Entrepreneurial mayors, who advocated the idea to "corporatise" the city and "leverage significant private investments", got wide international attention (Goldsmith, Giuliani and Daley 1999: I-15). Despite the emerged critical opposition, their model was multiplied anyhow elsewhere and in different forms. Hong Kong, the place where the 2017 
conference took place, had been the birthplace for a range of examples for this development with its public spaces in private developments which had been critically approached for two decades. New types emerged with deviating perceptions of public space (Cuthbert \& McKinnell, 1997: 308). This extended the debate to the city's public space in its ubiquitous shopping malls and private residential estates.

In chapter 'space' of this journal, we can read how the entrepreneurial city approach affects public space in our cities. Particularly by highlighting local residents versus respectively newcomers, tourists and event visitors here, the consequence of governmental action on the public space becomes clear. Analyses of the increasing density of Hong Kong's Mong Kok area, for example, showcases the effect of a fast changing role of the urban open space. In transforming districts like this one, the attractiveness of the street network, hence the quality of publicness, deteriorated, while on the micro level, public gathering has been directed simultaneously by real estate developers to their private premises. Large groups of people gather indoors. Following the opening of Olympic station in 1996 and Olympic City, series of malls opened between 1998 and 201 I, changing Mong Kok drastically. Not only, pedestrian footbridges go straight from these interior public spaces to the street network of neighbouring Mong Kok, but also within the Mong Kok district itself a large number of malls and arcades have opened in the plinths of privately-owned and gated high-rise tower developments. In this setting, existing local public life and entrepreneurial attitude seem more to cause conflicts. Who is benefiting from the spaces generated in the entrepreneurial city? We may question the same in cities such as New York City or Tokyo. Second, the urge to be attractive and competitive, by boosting tourism affects the public nature of open urban space too, as described in the paper on Lisbon. This seems to conflict with the desire to increase liveability. Governmental investments to make the city pedestrian-friendly may add to the vitality of the city, yet also arouses the interest of many travellers hunting for holiday destinations. After hosting international events between 1994 and 2004, boasting global visibility, subsequent entrepreneurial policies have made the city increasingly a tourist destination. Short stay visitors are more and more present in Lisbon's inner-city neighbourhoods Baixa, Chiado, and the Bairro Alto. Thus here, life in the outdoor public space has changed drastically. As the city becomes more appealing indeed, the question is again for whom? For sure, the same goes for specific areas in most visited cities around the world like Bangkok, Barcelona, or Istanbul. Third, following a similar desire to be competitive, while at the same token promote international cooperation and gathering, the recent case of Doha showcases the effects of popular world tournaments on public space. By highlighting the city's dedication to host the world's most watched sporting event, the 2022 FIFA World Cup and more recent the Club World Cup 2019, Doha has become recognised as a global hub and, in this slipstream, the design of new public spaces are made to meet universal standards. Within the public interiors of the soccer stadiums, as unveiled in the first 2010 plans, this may make sense because people from all continents will gather here. Yet, the public quality of the outdoor urban design in the already reconstructed areas of the partner cities Lusail and Al Wakrah may be critical, as public spaces are foremost based on imported western images. Also published artist impressions of the so-called Sports City and Doha Port seem to be disconnected from local use and culture. When considering the rise of the entrepreneurial approach Los Angeles, host of a familiar mega event - the 1984 Olympic Games - holds a pioneering position. Entrepreneurial practice has become part of 
urban tourism and new urban development strategies since (Spirou, 201 I: 68). Now, in the subsequent age of urbanisation, global travel, and world events, public spaces, created under entrepreneurial policies, are being tested. Again, the question reoccurs; for whom these spaces are designed?

\section{Entrepreneurial action of the people, inhabitants of the city}

The second observation regarding the 'entrepreneurial city' goes beyond the entrepreneurial role of public governments and large private corporations, and recognises the entrepreneurial contributions of general citizens, migrants and refugees and its relationship to public space. The concerns here are the initiatives of 'enterprising citizens' in places where government provisions lack. The historical roots of this entrepreneurial attitude might go back to "the collective self-help and community actions that characterised the ethos of early settler and farming communities, and that of many of the indigenous peoples before them" (Gass, 1989: 25). In modern times, similar behaviour became apparent in established societies present in established urban areas in transition or fastgrowing areas in the urban peripheries. Here on daily basis residents use their human wisdom and initiative to search for ways to improve their own as well as their community's livelihoods. Governments started to realise the benefits of these initiatives and began to encourage and promote entrepreneurship. For instance, David Cameron, as Prime Minister of the UK, highlighted in 2013 that "[s]ocial enterprises, charities and voluntary bodies have the knowledge, human touch and personal commitment to succeed where governments often fail" (Cameron, 2013, $6^{\text {th }}$ of June). Public policies encouraged citizens to act in a selfreliant or 'entrepreneurial' manner, and people, dependent on the public institutions, had to search for alternative action. This raised the question if they were equipped to do so. In the broader sphere, the education of societies towards collectives of entrepreneurial citizens had been started. For example in an Asian-Pacific review, UNESCO enhanced the vigour of exploration of the entry of "being enterprising", of "becoming doers", pervasively into the entire scope and sequence of general education (UNESCO Principal Regional Office for Asia and The Pacific 1994: i-iii). Following an African review of EDNA, a Dakarbased NGO holding a diplomatic status with the UN ECOSOC, public services at the grassroots should be stimulated. While representing an international network of community-based organisations and community movements, in their review, the 'entrepreneurial city' could consequently concern acting on citizens initiatives and on popular action: "The entrepreneurial city is based on a state of mind: on a positive popular imagination" (Gaye, 1996: 53-55). This extended the perspective of the entrepreneurial city to a different current reality of 'doers', who counterbalance governmental action or fill the gap between societal needs and governmental action and, as such produce public goods in demand. The 'entrepreneurial citizens' could be seen as people of all kinds active in changing societies, which might be dynamic in nature, unclear to some or less accessible for outsiders, or even continuously instable. As the 'Migrant Crisis' still continuous to dominate political discussion in Europe and North America, it seems important to explore how particular urban forms and spaces would either encourage or limit micro-economic opportunities. Sudden urban transformations into what Doug Sanders called 'arrival cities' had often been a shock for local population throughout recent history. Yet, they brought also new entrepreneurial economies, cultures and attractions. The resulting social mixing 
was considered to be beneficial for the entrepreneurial capital of cities (Saunders, 2012: 96, 306). For this discussion, Hong Kong was a compelling example for an 'arrival city' during the 2017 conference, which in its past was able to absorb - largely successful - millions of refugees and migrants despite its lack of natural resources and limited territory. It was a suitable example how the entrepreneurial spirit of its migrant population was a key driver in creating a highly efficient city. From trade to industrialisation to today's service economy, 'entrepreneurial citizens', old and new, in Hong Kong always seemed to turn to new tactics of survival (Chu, 1983: 168). Still, the opportunities, which the city offered were related to its early public spaces, characterized by the proximity of mixed land-uses and flexible building typologies, a well-connected street network and high density. Such characteristics concurred with the findings of the UN Habitat's report: 'Streets as Public Space and Drivers of Urban Prosperity' (UN-Habitat, 20I3). However, in Hong Kong and other cities, these qualities remained limited to the older urban fabrics, while large mono-functional housing estates and wide vehicular roads dominate the more recent 'New Development Areas'. A large share of Hong Kong's new public spaces don't provide anymore this ecosystem which allowed the 'enterprising citizen' to grow. It raises the ground for a second critical observation: Cities like Hong Kong seemed economically to prosper, while they became forbiddingly unaffordable low- and middle-income residents and reduced their economic opportunities, stifling social mobility and innovation. Furthermore, as an increasing number of people rely on short-term and self-employment they depend even more on their social networks and access to different clients, however, the spatial design and planning of the New Development Areas undercuts such opportunities (Tieben, 2016). While these trends are particularly pronounced in Hong Kong, they could be found in many places, which use similar development models and urban typologies, effecting public space in their socio-economic nature.

While recent political unrests in Hong Kong can't be explained solely by these spatial developments, a general sentiment of lack of opportunities and disempowerment can be linked to its planning model, which is closely linked to its socio-political order. It raises questions on the embeddedness of people in the entrepreneurial city. Not all citizens "have financial resources, technical capacities, or ties to other important actors that could contribute to the overall complement of resources" while the public government agencies provide access to public funding and certain public powers to compensate this if needed and generate and disseminate policy information too. So not everybody is embedded. Entrepreneurial citizens, who do interact and participate in the city, may actually be different citizen' actors that nave different interests. Others, who are not active in place or participating in processes, may still be entrepreneurial by influencing development from the outside and/or in alternative forms (Sullivan, 2000: 30, 60, 140). In chapter 'society' of this journal, we continue readings on the entrepreneurial citizen approach effecting public space in our cities in a different manner. In multivariate analyses, the ability to act as entrepreneurial citizens, and alternative ways to act entrepreneurial are studied. First, whereas Rio de Janeiro for decades has been an iconic city known for a local entrepreneurial culture, over the last decade it has promoted itself on the global stage by a series of mega-events, alike Doha today. In times of the 2007 Pan-American Games, the 2014 FIFA World Cup, and the 2016 Olympic Games, but also the United Nations Conference on Sustainable Development in 2012, the city embraced the 'city project' and started to improve the city's infrastructure. Despite this, proper infrastructure continues 
to lack in urban peripheral areas and, as public amenities are absent too, entrepreneurial citizens are actively involved in the creation of common spaces. What kind of space create entrepreneurial citizens? In these peripheral neighbourhoods, where the public government is less active, a local tradition of creating communal porches on the private premises as public spaces has surfaced again. These spaces emerge in multifunctional live-work units, in themselves reducing demands for transportation, while adding public spaces for social interaction. The new gathering places foster entrepreneurship, creativity and innovation. Secondly, entrepreneurial actions of the people, inhabitants of the city, can also be illuminated by comprehending who exerts power or has the power to act. It extends the issue of embeddedness. As displayed in the case of Taipei, spaces of 'counter-publics' are closer to citizens than so-called public parks which have been established by the municipal government. People are actively involved in the city's small-grain counter-public spaces. Entrepreneurial citizens created these places for communal interest. Government is bypassed. In contrast, people come to the big events and large-scale leisure activities in a formal park called Da-An. The public governmental agencies created this place in 1994 in order to meet the image of a central park in the global competitive city. Large self-made urban areas housed by squatter communities have been demolished for this park. While both kind of spaces are used well, in their conjunction another conflict in the entrepreneurial city come to the fore: the agency of the public government versus the agency of local citizens, the publics of concern. The entrepreneurial city may display an emerging parallelism. Thirdly, by extending the entrepreneurial city to hyper-divers liberal Amsterdam, a multiplicity in the concept unfolds. The public government of the city underpins concepts of the inclusive city, democratic city, and open city explicitly since the 2000 s, as part of their nature. Nevertheless, in this reasoning, from the angle of entrepreneurial citizens, in fact all inhabitants of the city, there does not exist one public space; an absolute public space for, of and by all people. On the contrary. Values conflict among them, as do powers. From that angle, 'agentiality', defined as people's ability to speak out' and act effectively in public spaces, becomes crucial. This may become relevant to understand public space in a growing number of more or less inclusive, democratic, and open entrepreneurial cities with more than a million foreign-born citizens, representing almost every nation of the world, like Toronto, San Francisco or London. Particularly by highlighting peripheral, or even segregated, communities, counter-publics and hyper divers settings, the consequence of citizens action on the public space becomes clear. This includes power, hence agency in space. Maybe, public spaces always echo diversities in societies. Similarly, the urban initiative is diverse. As these may come with conflicts, the search in the entrepreneurial city is to mediate.

\section{Entrepreneurial alliances of civic actors}

Lastly, there is a third observation regarding the relationship of the 'entrepreneurial city' and public spaces formed by new emerging alliances of actors, in response to the abovementioned conflicts and attempts to mediate. These new alliances of civil society groups comprise old and new NGO's, academics and activists, and start-ups of social enterprises, launching own initiatives to co-designs alternative community spaces, more affordable and communicative workspaces, and build capacities. Such trends can be seen in many cities and start to create new forms of public spaces, which facilitate social interaction, while creating 
more micro-economic opportunities. From the City's point of view these alliances of civic actors support entrepreneurial governmental actions. Being representatives of entrepreneurial cities, they promote a place-specific enterprise culture and society, with creative, flexible, and enterprising citizens (Hall and Hubbard, 1998: 89). From a citizen point of view, alliances increase innovation in entrepreneurial cities, reduce cost to operate, add to job creation and intensify participation. These alliances commonly follow grassroots footsteps originated in 'urban community enterprises' but in fact are a wide variety of agencies appearing in multiple combinations. Of these, particularly, partnerships between government, civil society, and NGOs support groups to allow entrepreneurial citizens to have greater access to public goods and services (Gass, 1989: 25, Gaye, 1996: 53-54). The emerging entrepreneurial alliances of civic actors include organisational and institutional features close to public agents in the city yet are close to an enterprising culture of community driven city makers. These are often quite in balance. Still, paradoxically, their initiatives may improve "the quality of life for all of a community's residents", yet also create revived places that "are inherently attractive enough to be sought out by the affluent.", as architect and urban planner Andres Duany reflected critically in The American Enterprise Magazine. In addition, urban entrepreneurialism creates frequently sameness (Griffiths, 1998: 4I-57, Duany, 200I: 36-39). Actions are aligned within the group and with the public government, while input from elsewhere, and promotion and exposure in the larger network might bend over to expected appreciated outcomes. In a critical review, one may include this concern that, as such, entrepreneurial alliances of civic actors may cause the displacement of people and through uniformity even placelessness, caused by. These critiques form a report on ways entrepreneurial communities develop the city for its citizens.

During the Hong Kong conference in 2017 , the city was presented as an urban environment where diverse entrepreneurial groups were highly active in the domain of public space. Often these groups are joined by professionals or have links to experts at least. Designing Hong Kong (formed in 2003), Central and Western Concern Group (2005), The Professional Commons (2007), Make a Difference (2009), Hong Kong Public Space Initiative (20II), Very Hong Kong (20I3) and Design Entrepreneurs Hong Kong (20I7), are not-random representatives of the remarkable long listing of enterprising groups which were formed to positively influence public space.

In chapter 'system' of this journal, we can read how the entrepreneurial alliances approach affects public space in our cities though their organisation. It underlines the power of 'access' too; making voices heard, including those who otherwise are in the shadow of shifting a small number of private corporate business actors. The first case study of Quanzhou underpins that entrepreneurial approaches in governmental policy may have a single focus on a global competitive city, serving tourism and consumption, but often may block potentials for stimulating civic action. The acceptance of a certain autonomy of groups in society and of public spaces - instead of seeing them all as one, with one mission, introduces pluralism and encourages public involvement. This stands in contrast to the provision and management of public spaces purely by one public authority, or at least adds to it. Since 2007, new cultural governance coalitions intended for 'remediation planning' in the historic sites of the ancient city of Quanzhou, protected as UNESCO World Heritage since 2018. This includes community participation, advocacy planning and other methods of engaging entrepreneurial civic alliances. In 2016, a conservation and development 
coordination group has been established to channel the implementation of those programmes. At the micro-level close to the public spaces that traditionally served local residents, entrepreneurial alliances are integrated into public governance. It states again the question: who creates what for whom? In our complex cities, displaying a multiplicity of socio-spatial systems, the answers are never simple. Actors and affected often cannot easily be identified only based on the geographical locality. Cases in smaller Thai and Philippine cities show how grassroots' engagement have the ability to build international networks in which the civic initiators rely on what has been successful elsewhere, or at least apply lessons learned elsewhere. In the unusual circumstances of the 2004 Indian Ocean Tsunami and the 2009 Typhoon Ketsana, the adaptive capacities of local communities have been tested. These devastating events have pushed community resilience in new forms of organising entrepreneurial citizens and civic agents. NGO, and community-led alliances have been strengthened by translocal networking, which may be a novel but paradoxical phenomenon wherein action in public space becomes locally specific while at the same moment are interlinked with far distant actors. The effects on public space in such cases display transboundary issues and images as well as local interpretations. In some views, entrepreneurial attitudes in place do not affiliate themselves to a territoriality at all. If public spaces are inclusive, democratic and agential, hence are the expression of open, collective and pluralistic associations, common worlds are various but still crucial. In cities like the illuminated case of Auckland in this chapter, or say Berlin, public spaces can be approached as hypermediated, because entrepreneurial alliances are multiscalar and overlapping, while they are establishing many virtual relations and perhaps personal perceptions through the presence of easy-access to digital networks. With 'the digital turn', enterprising people may be powerful. Enhancing this to understand public space might be challenging, yet also critical as it might dispose second lives. Despite this, any public space in the entrepreneurial city, formed by civic associations for mutual benefit, by relationship based on similarities or by any other joint partnership, can be best understood through the lens of civic alliances themselves. Influences of entrepreneurial alliances of civic actors are effectively results of specific coalitions and their authority, mediating between public government agents and enterprising citizens locally, as well as their world-wide networking and transductions in place.

The set of papers in this special issue illuminate our three observations regarding 'Public Space in the Entrepreneurial City'. These selections grew out of the conference, and are specific and unique case studies of conditions and approaches in different cities. Given the theoretical background of the theme, they open up perspectives on the ways in which the entrepreneurial city affects public space and how different actors address its challenges with the aim to make it more inclusive and share fairer its benefits and opportunities.

\section{References}

Bekkering, Henco, and Tieben, Hendrik (Eds.) (2019, April). "Urban design for an inclusive economy: part II," ICE Journal Urban Design and Planning, Themed Issue, Vol. I72, No.2, 45-46.

Bekkering, Henco, and Tieben, Hendrik (Eds.) (2018, December). "Urban design for an inclusive economy: part I," ICE Journal Urban Design and Planning, Themed Issue, Vol. I7I. No. 6, 229230.

Cameron, David (2013, $6^{\text {th }}$ of June). Cabinet Office in Prime Minister's speech at the Social Impact Investment Forum in London on 6 June 2013. Published online 6 June 2013: 
https://www.gov.uk/government/speeches/prime-ministers-speech-at-the-social-impactinvestment-conference, retrieved II November 2019.

Chu, David K.W. (1983). Hong Kong: A Business Profile, In: Farmer, Richard N., and John V. Lombardi (1983) Readings in international business. Bloomington: Cedarwood Press.

Cuthbert, Alexander R. \& McKinnell, Keith G. (1997), "Ambiguous space, ambiguous rights corporate power and social control in Hong Kong", Cities, Vol. I4, No. 5, 295-3II.

Duany, Andres (200I). "Three cheers for gentrification”, The American Enterprise, Vol. 12, No. 3 , April/May, pp. 36-39.

Gass, J. R. (1989). Towards an "enterprising" culture. A challenge for education and training. (Educational Monograph $\left.N^{\circ} 4\right)$ Paris: Organisation for Economic Co-Operation and Development (OECD) / Centre for Educational Research and Innovation.

Gaye, Malick (1996). Entrepreneurial cities, public services at the grassroots. (Occasional Papers No. 184-185). Dakar: ENDA Publications.

Griffiths, Ron (1998). Making sameness: Place marketing and the new urban entrepreneurialism. In: Oatley, Nick (ed.), Cities, economic competition and urban policy. London: Paul Chapman Publishing, Pp. 4I-57.

Goldsmith, Stephen, Rudolph W. Giuliani, and Richard M. Daley (1999). The entrepreneurial city: a how-to handbook for urban innovators. New York: Manhattan Institute for Policy Research (Center for Civic Innovation).

Harvey, David(1989). "From Managerialism to Entrepreneurialism: The Transformation in Urban Governance in Late Capitalism," Geografiska Annaler. Series B, Human Geography, Vol. 7I, No. I, The Roots of Geographical Change: 1973 to the Present, 3-17, 7.

Hall, Tim \& Hubbard, Phil(1998). The entrepreneurial city: geographies of politics, regime and representation, Chicester, England \& New York: Wiley.

Mollenkopf, John Hull (1983). The Contested City. New Jersey: Princeton University Press

Saunders, Doug (2012). Arrival City: How the Largest Migration in History Is Reshaping Our World, Vintage.

Spirou, Costas (20II). Urban tourism and urban change: Cities in a global economy. (The Metropolis and Modern Life). New York: Routledge.

Sullivan, Daniel Monroe (2000). Embeddedness and the Entrepreneurial City. (doctoral thesis) Madison: University of Wisconsin.

Tieben, Hendrik (2016).“Public Space Trends in Hong Kong. A View From The New Territories”, The Journal of Public Space, I (I), PP. 25-34.

UN-Habitat (2013). Streets as Public Spaces and Drivers of Urban Prosperity, Nairobi: UN-Habitat.

UNESCO Principal Regional Office for Asia and The Pacific (1994). Becoming Enterprising, Technical Guidelines, compiled by The Asia-Pacific Centre of Educational Innovation for Development (ACEID). Bangkok, UNESCO Principal Regional Office for Asia and The Pacific.

To cite this article:

Harteveld, M. and Tieben H. (2019). Public Space in the Entrepreneurial City. The Journal of Public Space, 4(2), I-8, DOI I0.3289I/jps.v4i2.I 20 I 